\title{
Equivalência Ricardiana e os Efeitos da Política Fiscal na Economia Brasileira
}

\section{Ricardian Equivalence and the Effects of Fiscal Policy in the Brazilian Economy}

Liderau dos Santos Marques Junior*

Resumo: Este artigo analisa os efeitos da política fiscal na economia brasileira no período de 1995 a 2009. Para tanto, apresenta a hipótese da equivalência ricardiana e discute as objeções teóricas. A partir de uma abordagem de vetor autorregressivo (VAR), analisa-se a resposta das variáveis poupança nacional/PIB e consumo privado/PIB a impulsos nas variáveis de política fiscal, carga tributária e consumo do governo/PIB. Os resultados indicam que os efeitos de choques na carga tributária não são ricardianos no caso brasileiro.

Palavras-chave: Política fiscal. Equivalência ricardiana. Modelo vetor autorregressivo.

Abstract: The paper investigates the effects of fiscal policy in Brazilian economy during the 1995-2009 period. For that, presents the ricardian equivalence hypothesis and discuss theoretical objections. From the vector autoregressive (VAR) approach, the paper analyzes the reaction of the variables national saving/GDP and private consumption/GDP to impulses in the variables of fiscal policy tax burden and government consumption/GDP. The results indicate that the effects of shocks in the tax burden are not ricardians in the Brazilian case.

Keywords: Fiscal policy. Ricardian equivalence. Vector autoregressive.

JEL Classification: C32; E6; E62.

\section{Introdução}

O debate sobre a importância da política fiscal e seus efeitos econômicos voltou à tona com o plano de estímulo fiscal de 2009 do Presidente Barack Obama no montante de US $\$ 787$ bilhões. Na discussão travada entre, de um lado, economistas como Paul Krugman e Christina Romer, que defendem medidas de política fiscal para tirar a economia norte-americana de uma depressão, e, de outro lado, autores como John Cochrane, John Taylor e Eugene Fama, que preconizam a ineficácia da política fiscal em produzir efeitos sobre o nível de produto da economia, reapareceu no centro do debate a hipótese da equivalência ricardiana (HER).

* Doutor em Economia pela Universidade Federal do Rio Grande do Sul (UFRGS). Analista pesquisador em Economia da Fundação de Economia e Estatística Siegfried Emanuel Heuser (FEE). E-mail: liderau@fee.tche.br 
Na versão de Barro (1989b), a HER propõe que, quando ocorre um aumento do déficit público, a menor poupança do governo é exatamente compensada por um aumento da poupança privada, de tal modo que a poupança nacional (ou doméstica) não se altera. Assim, o déficit público não tem efeitos sobre a atividade econômica e, por conseguinte, sobre o produto real da economia.

Os trabalhos de Barro (1989b), Bernheim (1987), Leiderman e Blejer (1988), Becker e Paalzow (1996), Vieira (2005) e Galí et al. (2007) analisam a HER e discutem suas objeções teóricas. Ademais, esses estudos fazem uma resenha da literatura empírica que busca testar os efeitos econômicos da política fiscal. A HER é testada considerando-se diversas abordagens, destacando-se as estimações da função consumo agregado e estimações a partir do problema do consumidor de maximização intertemporal da utilidade.

Os estudos de Sachsida e Carneiro (2001) e Sachsida e Carlucci (2010) testam a HER com dados da economia brasileira. Todavia, os resultados dos estudos são conflitantes. Sachsida e Carneiro (2001) concluem que os agentes respondem às mudanças na dívida pública de modo não compatível com o proposto pelo teorema ricardiano. Já Sachsida e Carlucci (2010), baseando-se em testes de exogeneidade, concluem que não importa a forma de financiamento do governo, os agentes não mudam de comportamento, logo os resultados sugerem a aceitação da HER.

Vieira (2005) também faz uma resenha dos estudos empíricos que buscam testar a HER e trabalha com dados para a economia brasileira. O autor utiliza dados em termos per capita e analisa o período do primeiro trimestre de 1991 ao primeiro trimestre de 2005. A partir de diferentes procedimentos de testes empíricos, ele conclui que não há validade da HER para o Brasil. A razão básica reside na restrição de liquidez a que estão sujeitos grande parcela dos consumidores brasileiros.

Mendonça et al. (2009) adotam um determinado procedimento de identificação para analisar os efeitos de choques fiscais na economia brasileira. Entre os resultados obtidos, destaca-se a conclusão de que um aumento inesperado do gasto do governo tem como resposta um aumento do consumo privado, o que contraria a HER.

Peres e Ellery Jr. (2009) analisam os efeitos de choques fiscais do governo central sobre a atividade econômica no Brasil no período 1994 a 2005. A partir de um vetor autorregressivo estrutural (SVAR), concluem que a resposta do produto aos choques fiscais é tipicamente keynesiana: é positiva diante de um choque nos gastos e negativa no caso de choque nos impostos.

Baseando-se em Favero e Giavazzi (2007), Cavalcanti e Silva (2010) consideram o papel da dívida pública na evolução das variáveis fiscais no caso da economia brasileira no período de 1995 a 2008. Os resultados obtidos sugerem que os 
efeitos de choques fiscais no nível de produto são superestimados quando não se leva em conta a razão dívida/PIB no modelo SVAR.

Moreira (2010) analisa os efeitos da política fiscal no Brasil para o período do primeiro trimestre de 1995 ao terceiro trimestre de 1998. Os resultados indicam que a dívida pública tem um papel importante na determinação das variáveis demanda real por moeda, razão investimento/PIB e hiato do produto. Assim, as evidências não corroboram a HER no caso do Brasil.

Não se tem espaço para analisar cada estudo ressaltando os pontos fracos e fortes, todavia, a maioria dos estudos sugere que os efeitos da política fiscal não são ricardianos no caso da economia brasileira.

O presente trabalho tem como objetivos discutir parte da literatura que analisa os efeitos da política fiscal e apresentar uma análise empírica na qual se testa a validade da HER, com os dados do Brasil, propondo-se a abordagem do modelo vetor autorregressivo com correção de erros (VEC). Utiliza-se tal abordagem porque permite analisar a resposta das variáveis consumo privado/PIB e poupança nacional/PIB a choques nas variáveis fiscais (carga tributária e gastos públicos/PIB). Ademais, se analisa se as variáveis em estudo (carga tributária, gastos públicos/ $\mathrm{PIB}$, consumo privado/PIB e poupança nacional/PIB) têm uma dinâmica comum e, por conseguinte, se têm um componente de longo prazo e um de curto prazo. $\mathrm{O}$ período analisado compreende do primeiro trimestre de 1995 ao quarto trimestre de 2009.

O artigo está assim dividido: na segunda seção se analisa a HER; na terceira seção discutem-se as diversas objeções teóricas ao argumento ricardiano; na quarta seção são analisadas as três principais abordagens (ricardiana, neoclássica e keynesiana) que discutem os efeitos da política fiscal; na quinta seção aborda-se a parte empírica do trabalho, em que são analisadas as séries trimestrais de consumo do governo, consumo das famílias, carga tributária e poupança nacional bruta (todas em relação ao PIB) para o período que compreende do primeiro trimestre de 1995 ao quarto trimestre de 2009; e, por fim, na quinta e última seção, tecem-se as considerações finais.

\section{A Hipótese da Equivalência Ricardiana}

Na versão de Barro (1989a, 1989b e 1997), a HER propõe que a política fiscal não tem efeito sobre a atividade econômica. Essa proposição é obtida com base no seguinte argumento: dada uma trajetória de gastos públicos, a riqueza líquida das famílias em valor presente não é afetada pela política fiscal.

Os supostos da abordagem ricardiana são os seguintes: a) os impostos são do tipo lump-sum; b) o déficit público é financiado através de emissão de títulos públicos; c) a taxa de juros paga pelo governo é a mesma obtida pelo setor privado; 
d) os setores (público e privado) têm igual horizonte de planejamento; e e) tem-se total certeza sobre a política fiscal do governo. Becker e Paalzow (1996) explicitam os demais supostos da abordagem: a) os agentes são racionais e têm visão de longo prazo; b) os custos associados à emissão e ao serviço da dívida são nulos ou irrisórios; c) a trajetória e o valor presente dos gastos do governo não são afetados pela ocorrência de déficits ou superávits públicos; d) o consumo dos agentes é determinado solucionando-se o problema intertemporal de maximização da utilidade; e) os mercados de capitais ou de crédito são perfeitos; e f) todos os mercados encontram-se em equilíbrio e há pleno emprego dos recursos.

A restrição orçamentária do governo no período $t$, em termos reais, é dada por:

$$
G_{t}+r_{t-1} B_{t-1}=T_{t}+\left(B_{t}-B_{t-1}\right)
$$

em que $G_{t}$ são os gastos do governo (incluindo transferências); $B_{t}-1$ é o estoque da dívida pública ao final do período $t-1 ; r_{t-1}$ é a taxa de juros real sobre a dívida pública; e $T_{t}$ é a receita tributária.

A restrição orçamentária da família representativa no período $t$, em termos reais, é assim expressa:

$$
w_{t}+b_{t-1}\left(1+r_{t-1}\right)+v_{t}=t_{t}+c_{t}+b_{t}
$$

em que $w_{t}$ é o salário real no período $t$; $b_{t}$ é o montante de dívida pública em poder da família ao final do período $t$; $v_{t}$ são as transferências lump-sum para a família; $t_{t}$ é o imposto lump-sum sobre a família; e $c_{t}$ é o consumo da família no período $t$.

O fator valor presente, $d_{t}$, é definido por:

$$
d_{t}=\frac{d_{t-1}}{1+r_{t-1}}
$$

para $t=1,2, \ldots$ e $d_{0}=1$.

A restrição orçamentária da família em valor presente com horizonte finito H é assim expressa:

$$
b_{0}+\sum_{1}^{H} d_{t} w_{t}+\sum_{1}^{H} d_{t} v_{t}=\sum_{1}^{H} d_{t} c_{t}+\sum_{1}^{H} d_{t} t_{t}+d_{H} b_{H}
$$


Quando $H$ tende ao infinito, o último termo, à direita na equação 4 , tende a zero. Portanto, a restrição orçamentária da família em valor presente com horizonte infinito é: ${ }^{1}$

$$
b_{0}+\sum_{1}^{\infty} d_{t} w_{t}+\sum_{1}^{\infty} d_{t} v_{t}=\sum_{1}^{\infty} d_{t} c_{t}+\sum_{1}^{\infty} d_{t} t_{t}
$$

No agregado, a riqueza líquida das famílias em valor presente depende da dívida pública inicial, $B_{0}$, do valor presente das transferências e do valor presente dos impostos:

$$
B_{0}+\sum_{1}^{\infty} d_{t} V_{t}-\sum_{1}^{\infty} d_{t} T_{t}
$$

Supondo-se $V_{t}=0$ em cada período, a riqueza líquida das famílias em valor presente depende apenas da dívida pública inicial e do valor presente dos impostos:

$$
B_{0}-\sum_{1}^{\infty} d_{t} T_{t}
$$

Todavia, da equação 1 e considerando-se que $\lim _{H \rightarrow \infty}\left(d_{H} B_{H}\right)=0$, ou seja, que a restrição intertemporal do governo é satisfeita, tem-se que a riqueza líquida das famílias em valor presente depende da dívida pública inicial, $B_{0}$, do valor presente dos impostos e do valor presente dos gastos: ${ }^{2}$

$$
B_{0}-\sum_{1}^{\infty} d_{t} T_{t}=-\sum_{1}^{\infty} d_{t} G_{t}
$$

Portanto, somente o valor presente dos gastos (dados exogenamente) afeta a riqueza líquida das famílias. Por conseguinte, as escolhas de consumo das famílias não dependem dos impostos. A forma como o governo financia seus gastos não tem efeitos reais sobre a economia. Esse resultado é uma versão do teorema da equivalência ricardiana.

$1 \quad$ Leiderman e Blejer (1988) apresentam um modelo de dois períodos.

2 A demonstração dessa afirmação pode ser encontrada em Barro (1989a, p. 203). 
A política fiscal afetará a riqueza líquida das famílias em valor presente e, consequentemente, as suas decisões de consumo se o valor presente dos impostos for alterado. Isso ocorrerá se o governo alterar o valor presente dos gastos. Assim, alterações nos gastos correntes e futuros que impliquem mudança no valor presente dos gastos públicos e, por conseguinte, no valor presente dos impostos, mesmo satisfazendo-se a restrição intertemporal do governo, produzirão efeitos sobre a riqueza líquida das famílias em valor presente.

Outra versão do teorema da equivalência ricardiana pode ser exposta considerando dois períodos. Dada uma trajetória de gastos do governo, um corte nos impostos hoje gera um déficit público cujo financiamento se dá via a emissão de títulos públicos, que, por sua vez, são totalmente adquiridos pelas famílias. Amanhã, a fim de resgatar a dívida pública, o governo eleva os impostos e as famílias pagam essa maior carga de impostos com os títulos públicos comprados ontem, acrescidos dos juros. Como o valor presente dos impostos não se alterou, a trajetória de consumo das famílias não foi afetada, porque a aquisição dos títulos públicos não representou aumento de riqueza líquida para as famílias. ${ }^{3}$

Visando-se explicitar ainda mais o argumento ricardiano, considere o seguinte exemplo: supondo-se que a dívida pública no período zero é igual a zero, ou seja, $B_{0}=0$, e que, no período 1 , o governo reduz a arrecadação de impostos, $T_{1}$, em uma unidade $\$ 1$, isso gera um aumento da renda disponível agregada das famílias no período 1 em $\$ 1$ e um déficit também de $\$ 1$. O resultado ricardiano implica que as famílias, ao invés de elevarem o consumo em $\$ 1$, compram esse montante em títulos da dívida pública, $B_{1}=1$. Assim, o déficit público é totalmente financiado com dívida pública. As famílias se comportam dessa maneira porque, dada a trajetória de gastos do governo, uma redução em $\$ 1$ de impostos no período 1 implica aumento de $\$ 1$ no valor dos impostos futuros. Dessa forma, o efeito de tal variação sobre o valor presente dos impostos é nulo. Portanto, uma redução na poupança do governo levou a um aumento de igual magnitude na poupança privada desejada, de tal modo que a poupança nacional não se alterou. Se o valor

3 Nota-se que se a trajetória dos impostos é dada e há um aumento de gastos públicos no presente, o déficit público é financiado por emissão de títulos públicos que são adquiridos pelas famílias; os títulos públicos são adquiridos via redução do consumo corrente. Amanhã, a fim de resgatar a dívida pública, o governo reduz os gastos públicos e as famílias elevam o consumo vendendo os títulos comprados ontem, acrescidos dos juros. Como o valor presente dos gastos não se alterou, então a riqueza líquida das famílias em valor presente mantem-se inalterada. Galí et al. (2007, p.228) resume assim o teorema: "Ceteris paribus, an increase in government spending lowers the present value of after-tax income, thus generating a negative wealth effect that induces a cut in consumption." Este trabalho assume que os consumidores gastam toda a renda corrente, assim não tomam empréstimos nem poupam. Tal comportamento pode ser atribuído a uma combinação de miopia, falta de acesso aos mercados financeiros e restrições impostas na tomada de empréstimos. 
presente dos impostos se alterasse, a trajetória de consumo das famílias também mudaria. ${ }^{4}$

Blanchard (2004) destaca o papel das expectativas das famílias. Uma longa sequência de déficits públicos, e o consequente aumento da dívida pública de um país, não são motivos de preocupação desde que a despoupança do governo seja compensada por uma elevação igual da poupança privada, mantendo-se a poupança total inalterada e, por conseguinte, o investimento da economia. Para que isso ocorra, as famílias tomam suas decisões de consumo levando em conta não só a renda atual, mas também a renda futura. Dada a expectativa de maiores impostos no futuro, a poupança privada cresce, reduzindo-se o consumo das famílias, de modo a compensar a queda da poupança do governo, mantendo-se inalterada a poupança nacional.

\section{Objeções Teóricas à Equivalência Ricardiana}

Barro (1989b), Bernheim (1987), Leiderman e Blejer (1988) e Becker e Paalzow (1996) fazem um apanhado das objeções teóricas à equivalência ricardiana e dos estudos empíricos que testam os efeitos econômicos da política fiscal.

A primeira objeção afirma que as pessoas não vivem para sempre, ou seja, o tempo de vida é limitado e, portanto, não se preocupam com a arrecadação de impostos após a sua morte. Em outras palavras, os agentes têm um horizonte de planejamento que não é infinito ou, ao menos, menor do que o do governo. Daí a ausência de elos entre as gerações. Outros fatores apontados para a ausência de elos entre as gerações são: a) a preocupação das famílias com os seus descendentes não é suficientemente forte a ponto de deixarem heranças positivas; b) boa parcela da sociedade não se preocupa em poupar, seja por falta de renda, seja em razão de um comportamento consumista; c) o tempo de vida de cada indivíduo é incerto; e d) a ocorrência de choques como doenças, acidentes e falências levam as famílias a não deixar heranças positivas. ${ }^{5}$ Assim, uma geração qualquer corre o risco de não ter fundos (títulos mais juros acumulados) suficientes para arcar com o aumento de impostos necessários para resgatar a dívida assumida.

Na presença de incerteza quanto ao tempo de vida, e assumindo a ausência de elos entre gerações ou entre as famílias e seus descendentes, um corte de impostos no período corrente implicará elevação da riqueza líquida e, por conseguinte, do consumo das famílias. Segundo Becker e Paalzow (1996), o mesmo efeito pode ocorrer caso as famílias realizem substituições intertemporais incorre-

$4 \quad$ Para uma exposição didática do argumento, ver Blanchard (2004) e Heijdra (2009).

5 Essas suposições são mais realistas do que as seguintes: a) as famílias ou indivíduos preocupam-se tanto com seus descendentes que deixam heranças positivas; e b) com certeza, cada geração lega heranças positivas suficientes para que uma geração qualquer use esses fundos para honrar a dívida passada. 
tas e equivocadas dos recursos futuros em relação aos correntes. Essa suposição é bastante razoável considerando-se que as famílias, por diversas razões, perdem oportunidades existentes hoje ou superestimam a probabilidade de maiores ganhos futuros.

A segunda objeção refere-se às motivações que as famílias têm ao realizarem transferências para os indivíduos de outras gerações. Assumindo-se a existência de outras motivações para as transferências voluntárias aos descendentes, ${ }^{6}$ além do altruísmo, pode acontecer uma situação em que as transferências não sejam suficientemente elevadas de modo a compensarem o aumento de impostos necessário para resgatar a dívida pública legada pelas gerações passadas. Supondo-se um corte de impostos hoje capaz de elevar a riqueza líquida das famílias, nesse caso o consumo e a poupança privada se elevam, entretanto o aumento na poupança privada pode não compensar a queda da poupança pública, o que terá como efeito uma redução da poupança nacional. ${ }^{7}$

A terceira objeção argumenta que os mercados de crédito são imperfeitos ou que há restrições à concessão de empréstimos para determinados setores (ou grupos) em função dos custos de transação. Com mercados de crédito perfeitos, se a família desejar transferir renda ao longo do tempo, com o objetivo de maximizar intertemporalmente a sua função utilidade, poderá fazê-lo tomando empréstimos ou emprestando recursos à mesma taxa paga pelo governo. Conforme Becker e Paazlow (1996), a suposição de que os mercados de crédito são perfeitos está associada a um outro suposto, a saber, o de que não existe problema de informação entre os tomadores de empréstimos e os intermediários financiadores, assim não é necessário adicionar um prêmio de risco sobre as taxas de juros. Contudo, admitindo-se a assimetria de informação entre tomadores de empréstimos e intermediários financeiros, haverá diferentes taxas de juros para os mais diversos setores ou grupos.

Para Becker e Paazlow (1996), mercados de crédito perfeitos implicam famílias não sujeitas a restrição de liquidez. Se isso fosse verdadeiro, qualquer família poderia comprometer sua renda futura sem precisar de maiores garantias. Entretanto, quando se leva em conta que muitas famílias têm pouca ou nenhuma garantia, um corte de impostos, financiado por dívida, irá aliviar a restrição de liquidez, o que alterará o consumo corrente das famílias.

6 Além do altruísmo, a literatura econômica considera a existência de outras motivações, tais como incerteza em relação à duração da vida, generosidade e transferências por morte repentina.

7 Numa economia fechada, a redução da poupança nacional implica elevação da taxa de juros real e, portanto, redução na formação de capital. Numa economia aberta e pequena, a implicação seria uma maior entrada de capital estrangeiro, apreciação da taxa de câmbio real e, por conseguinte, deterioração da conta corrente. Em ambas as situações se têm importantes efeitos econômicos da política fiscal. 
Supondo-se uma economia fechada e dois grupos de agentes, tem-se a seguinte situação: o grupo A tem fácil acesso ao crédito (grandes empresas, fundos de pensão e famílias de renda alta) e o grupo B tem difícil acesso ao crédito (pequenas empresas e famílias de renda baixa). O grupo A e o governo têm a mesma taxa de desconto, já o grupo $\mathrm{B}$ tem uma taxa de desconto maior do que a do governo. Então, se o governo cortar impostos correntes, o grupo A adquire sua parte de títulos públicos e sua riqueza líquida não se altera. Porém, o grupo B melhora de situação porque lhes é permitido tomar empréstimos à taxa de juros do governo, o que motiva seus membros a elevar o consumo e o investimento corrente. No agregado, a referida mudança na política fiscal eleva a demanda agregada.

A quarta objeção refere-se ao suposto de que a família representativa detém perfeito conhecimento sobre a equivalência entre impostos correntes e dívida pública como formas alternativas de financiamento das contas do governo. Assumindo-se perfeito conhecimento, a família representativa sabe que mudanças na política fiscal não afetam sua riqueza líquida. De acordo com isso, considera-se o seguinte exemplo: dada uma taxa de juros de mercado de $10 \%$, o imposto no montante de $\$ 100$ sobre uma família é substituído por uma dívida que estabelece a obrigação de um pagamento de $\$ 10$ em juros por ano. Nesse caso, a mudança de instrumentos de financiamento não afeta a riqueza líquida da família. Para Buchanan e Wagner (1999), não se pode negligenciar as exigências em termos de informação para que a família representativa se mantenha indiferente quanto às formas alternativas de financiamento do governo. Para a família representativa se manter indiferente entre as diferentes formas de financiamento, ela deve conhecer o sistema tributário, as competências de arrecadação de cada imposto, assim como o perfil dos diversos tipos de títulos públicos negociados no mercado financeiro. Diante da complexidade de tais assuntos, torna-se difícil sustentar a indiferença da família representativa entre impostos e endividamento público.

A quinta objeção afirma que a incerteza sobre quem recairão os impostos futuros implica uma alta taxa de desconto na capitalização desses compromissos futuros. Assim, se houver redução de impostos correntes, a riqueza líquida das famílias altera-se, bem como o comportamento quanto ao consumo. Leiderman e Blejer (1988) afirmam que é muito forte supor que as famílias sabem com antecedência quando haverá elevação dos impostos, quais os tipos de impostos que serão majorados e o montante do aumento da carga tributária, visando compensar a redução de impostos ocorrida hoje. Em outras palavras, é muito forte supor que as famílias preveem perfeitamente a sua renda, os impostos e os gastos futuros do governo. Levando-se em conta tais fontes de incerteza, a redução de impostos correntes produz mudanças de comportamento em termos de consumo por parte das famílias, daí se segue que a política fiscal tem efeitos econômicos importantes. 
A sexta objeção argumenta que os impostos não são lump-sum, isto é, os impostos recaem sobre uma determinada base (consumo, patrimônio e renda) e, portanto, afetam as decisões dos agentes econômicos. Mudanças no timing dos impostos provocam alterações nos preços relativos de bens de consumo e dos fatores de produção e, por conseguinte, acarretam os efeitos substituição e renda. ${ }^{8}$ Nesse contexto, a política fiscal afeta os incentivos para as pessoas trabalharem, produzirem e consumirem ao longo do tempo, bem como as decisões das firmas. Portanto, mudanças na política fiscal não são neutras. Se os impostos não são lump-sum, uma redução hoje, por exemplo, do imposto sobre a renda elevará o esforço de trabalho das famílias no período corrente e o reduzirá no futuro quando o imposto sobre a renda se elevar. Portanto, o timing dos impostos tem impactos sobre as decisões de consumo e poupança das famílias.

A sétima objeção afirma que, de um lado, o governo não é um simples coletor de impostos lump-sum e, por outro lado, os gastos do governo não são lump-sum. De fato, tantos os impostos quanto os gastos têm efeitos sobre a distribuição de renda. Ademais, os gastos do governo não são exógenos como propõe a HER. O montante e a estrutura de gastos dependem de decisões políticas, e estas, por sua vez, são afetadas por resultados eleitorais e por pressões de grupos de interesses. Então, admitindo-se que a trajetória dos gastos não é dada exogenamente, assim como a trajetória dos impostos, a política fiscal produz efeitos econômicos relevantes.

A oitava e última objeção leva em conta a probabilidade de um governo promover um calote da dívida ou adiar a elevação dos impostos e, assim, não honrar seus compromissos com as famílias. Se há incerteza sobre o comportamento futuro do governo em relação à dívida pública, então, de um lado, as famílias exigirão um prêmio de risco sobre os títulos públicos e, de outro lado, aquelas avessas ao risco elevarão sua poupança, reduzindo o consumo corrente. Portanto, a política fiscal produz efeitos econômicos importantes. A história econômica de diversos países mostra que a probabilidade de um governo não honrar seus compromissos não é nula.

As objeções sugerem que a política fiscal importa. Na seção seguinte analisam-se os possíveis canais da política fiscal através dos quais são produzidos efeitos econômicos.

8 Mudanças nos níveis e nos tipos de impostos também provocam os efeitos substituição e renda. 


\section{Efeitos da Política Fiscal}

A literatura econômica sobre os efeitos da política fiscal sobre os agregados econômicos, em particular os efeitos dos déficits públicos, é bastante extensa. ${ }^{9} \mathrm{De}$ fato, os efeitos são ambíguos do ponto de vista teórico.

Sob o ponto de vista neoclássico, uma elevação nos gastos do governo elevará os impostos futuros sobre as famílias, sendo que tal elevação reduzirá o valor presente da renda disponível das famílias e, por conseguinte, o consumo privado se reduz. É importante notar que um aumento nos gastos do governo acarreta um maior valor presente dos impostos e, por conseguinte, uma diminuição do valor presente da renda disponível das famílias desde que a restrição orçamentária intertemporal do governo seja obedecida. Portanto, na visão neoclássica, a correlação entre consumo privado e consumo do governo é negativa. ${ }^{10}$

No mundo keynesiano, o aumento dos gastos públicos ou a redução de impostos eleva a demanda agregada, que, através do efeito multiplicador, eleva a renda da economia. Consequentemente, o consumo privado também aumenta. Embora não seja um pressuposto, o argumento keynesiano é compatível com a hipótese de equilíbrio orçamentário intertemporal do governo. Portanto, na abordagem keynesiana, a correlação entre consumo privado e os gastos públicos é positiva. ${ }^{11}$

Quanto à relação entre impostos e consumo privado, tanto o ponto de vista neoclássico quanto o keynesiano concorda que, qualquer que seja a causa de uma elevação dos impostos, o que se espera como efeito é a redução do consumo privado em razão de uma diminuição na renda disponível das famílias. Portan-

9 Bernheim (1989), Barro (1989b), Eisner (1989), Gramlich (1989) e Yellen (1989) estabelecem uma ampla discussão sobre as diferentes abordagens que investigam os efeitos econômicos da política fiscal. Galí et al. (2007) discutem os efeitos da política fiscal levando em conta somente duas abordagens: a teoria dos ciclos econômicos reais e o modelo IS-LM.

10 Contudo, Cavalcanti e Silva (2010) assinalam que o que a visão neoclássica preconiza depende do tipo de tributos. Se a taxação não for distorciva (impostos lump-sum), o aumento de gastos públicos eleva a oferta de trabalho e, por conseguinte, o produto se eleva; se a taxação for distorciva, tem-se queda do produto porque o aumento dos gastos públicos gera desestímulo ao trabalho e ao investimento.

11 Essa mesma conclusão é obtida ao se admitir que o consumo do governo é complementar ao consumo privado. Supondo-se que o consumo do governo seja direcionado para constituir um bom sistema legal, nesse caso os consumos, privado e público, são complementares. Jönsson (2004) observa que um bom sistema legal reduz os custos de transação na economia. Como consequência, o consumo privado aumentará. Galí et al. (2007) desenvolvem um modelo de equilíbrio geral estocástico e dinâmico em que uma expansão nos gastos públicos, dadas as trajetórias dos impostos e da taxa de juros real, tem o potencial de elevar o consumo agregado, resultando em elevação da demanda agregada, do produto e do emprego. Ademais, supondo-se uma rigidez dos preços e que a grande parcela das famílias não se endivida ou poupa, isto é, que as famílias que gastam toda a renda disponível em consumo, os autores encontram evidências de que um choque positivo nos gastos do governo está associado a um significativo aumento no consumo das famílias. 
to, segundo Jönsson (2004), espera-se uma correlação negativa entre impostos e consumo privado. Para o autor referido, o mesmo acontece com as transferências, ou seja, um aumento nas transferências leva a uma redução do consumo privado, isso porque se as transferências aumentam, os impostos também se elevam, o que reduz o valor presente da renda disponível das famílias. Consequentemente, o consumo privado é menor.

Becker e Paalzow (1996) comentam que, do ponto de vista neoclássico, se a redução dos impostos hoje for maior do que o aumento no valor presente dos impostos futuros, mantendo-se a trajetória dos gastos do governo, então o consumo e a poupança privada se elevam. Todavia, o aumento na poupança privada não é suficiente para compensar o declínio na poupança pública, consequentemente a poupança nacional decresce. Evidentemente, o tamanho dos efeitos mencionados depende da diferença entre a mudança nos impostos hoje e a variação no valor presente dos impostos futuros.

Ainda segundo Becker e Paalzow (1996), do ponto de vista keynesiano, uma mudança no timing dos impostos irá afetar o consumo privado corrente. Caso ocorra uma redução dos impostos hoje, o consumo privado aumenta porque a renda disponível corrente se elevou e, através do efeito multiplicador, a renda aumenta. É claro que os efeitos sobre o consumo privado dependem do tamanho da redução dos impostos. Supondo-se que uma redução dos impostos correntes gere um déficit público, que é financiado através da emissão de títulos públicos, nessa situação, se as taxas de juros se elevarem, os investimentos privados se reduzem, diminuindo o impacto sobre a renda gerado pela maior renda disponível. ${ }^{12}$

Uma visão alternativa sobre a relação entre política fiscal e a trajetória do consumo privado é apresentada por Giavazzi e Pagano (1995). Segundo eles, a política fiscal atual afeta as expectativas dos agentes sobre a política fiscal futura. Assim, uma contração fiscal pode sinalizar uma redução permanente nos gastos do governo e, portanto, menores impostos futuros. ${ }^{13}$ Admitindo-se que os impostos são distorcivos, a contração fiscal implica não só maior renda disponível futura, o que eleva o consumo privado, como também, em função de menores distorções, maior estímulo ao investimento privado. Assim, a contração fiscal tem como efeitos a elevação do consumo privado e da atividade econômica.

Na visão ricardiana, pressupondo-se equilíbrio orçamentário intertemporal do governo e uma dada trajetória de gastos públicos, uma redução dos impostos

12 Eisner (1989) argumenta que o déficit não necessariamente desloca o investimento privado. Para ele, o aumento na demanda agregada leva a um aumento da lucratividade dos investimentos privados, assim, o que se tem é um maior nível de investimento privado, dada uma taxa de juros. Jönsson (2004) esclarece que períodos de grandes e/ou prolongadas mudanças na política fiscal podem ser classificados como expansão ou contração fiscal dependendo da mudança no déficit fiscal: contração fiscal é quando se tem períodos de redução do déficit fiscal, e expansão fiscal se caracteriza por períodos de elevação do déficit fiscal. 
correntes não tem efeito sobre o consumo privado, pois a maior renda disponível por parte das famílias é totalmente alocada em títulos públicos, ou seja, a elevação na poupança privada compensa a queda na poupança pública de modo que a poupança nacional mantém-se inalterada. Portanto, o déficit público ou a dívida pública não tem efeitos sobre a atividade econômica. ${ }^{14} \mathrm{Na}$ visão neoclássica, diferentemente do que propõe a abordagem ricardiana, as famílias tomam suas decisões de consumo sem levar em conta a restrição orçamentária intertemporal do governo. Assim, dada uma trajetória de gastos públicos, uma redução de impostos estimula mais o consumo privado do que a poupança privada. Como o aumento da poupança privada não compensa a queda na poupança pública, a poupança nacional decresce. Portanto, o produto da economia se reduz. Por último, na visão keynesiana, admitindo-se o equilíbrio orçamentário intertemporal, uma redução nos impostos correntes eleva o consumo privado corrente e, por conta do efeito multiplicador, a renda da economia. A elevação da poupança privada supera a queda da poupança pública de modo que a poupança nacional se eleva. ${ }^{15}$

Muitos estudos discutem os efeitos da política fiscal sobre o nível de atividade e apresentam testes sobre a validade da HER. Os estudos empíricos não são conclusivos a respeito dos efeitos da política fiscal sobre o nível de produto. Bernheim (1987), Seater (1993) e Galí et al. (2007) são exemplos de trabalhos que apresentam resumos das análises empíricas. Para o caso brasileiro, já se fez referência aos trabalhos de Sachsida e Carneiro (2001), Vieira (2005) e Moreira (2010). Na seção seguinte propõe-se uma análise empírica que visa investigar a validade da HER com dados para o Brasil.

\section{Análise Empírica}

A partir da discussão teórica, a HER pode ser resumida em duas proposições: a) dada uma trajetória de gastos públicos, o consumo das famílias não é afetado por mudanças no timing dos impostos; b) dada uma trajetória de gastos públicos, alterações no timing dos impostos afetam a poupança privada, contudo a poupança doméstica não se altera. Consequentemente, não se tem efeitos reais sobre o produto da economia.

Então, com base nas duas proposições teóricas, as variáveis endógenas consideradas na análise VEC são quatro (todas em relação ao PIB): consumo privado

14 De acordo com Barro (1989b), se os agentes percebem os títulos públicos como riqueza líquida, então um aumento do déficit público está associado a uma redução da poupança doméstica. A redução na poupança nacional gera um aumento da taxa de juros e, por conseguinte, a redução do estoque de capital.

15 Conforme Becker e Paalzow (1996), três supostos são fundamentais para o resultado keynesiano: a) os consumidores tem visão de curto prazo, portanto não se preocupam com o futuro; b) os consumidores estão sujeitos às restrições de liquidez; e c) a economia opera numa situação abaixo do pleno de emprego. 
(c); carga tributária (t); gastos (consumo) do governo (g); e poupança nacional (s). Considerando-se esse conjunto de variáveis, a HER pode ser assim reformulada: ${ }^{16}$

a) dada a relação gastos públicos/PIB, variações na carga tributária não têm efeitos sobre a relação consumo privado/PIB;

b) dada a relação gastos públicos/PIB, a relação poupança nacional/PIB (= poupança das famílias + poupança do governo) não é afetada por variações na carga tributária.

Os dados trimestrais do consumo final das famílias, do consumo final da administração pública, da poupança nacional bruta e do PIB foram obtidos tem como fonte IBGE (2006). Os dados trimestrais da carga tributária bruta tem como fonte Santos et al. (2010). O período em análise compreende do primeiro trimestre de 1995 ao quarto trimestre de 2009. ${ }^{17}$ Não foi possível usar séries mais longas devido à inexistência de dados referentes ao da carga tributária bruta. As séries foram dessazonalizadas pelo método X-12 multiplicativo. ${ }^{18}$

O Gráfico 1 apresenta a série trimestral do consumo privado (c) sem e com ajuste sazonal (c_SA) em relação ao PIB. A tendência da série com ajuste sazonal foi obtida através do filtro de Hodrick-Prescott. A série apresenta sazonalidade e uma tendência de queda a partir de 1999, estabilizando-se em torno de $60 \%$ do PIB a partir do segundo trimestre de 2008.

16 Deve-se lembrar que a poupança doméstica é assim definida: $S_{D}=S_{p}+S_{g}$, em que $S_{p}$ é a poupança privada e $S_{g}$ é a poupança do governo. A poupança privada é definida da seguinte forma: $S_{p}=Y-T-C$, em que $Y$ é o produto da economia; $T$ é a arrecadação de tributos; $Y-T$ é a renda disponível do setor privado; e $C$ é o consumo privado. A poupança do governo é definida como: $S_{g}=T-G$, em que $G$ representa os gastos públicos. Substituindo-se as definições das poupanças privada e pública na definição da poupança doméstica, tem-se: $S_{D}=Y-T-C+T-G$. Dividindo-se por $Y$, tem-se: $S_{D} / Y=(Y-T) / Y-C / Y+T / Y-G / Y$. Quatro motivos levaram à decisão pela exclusão da variável renda disponível da análise. Primeiro, o VAR ampliado, que inclui a relação renda disponível/PIB sugerido pelos critérios de informação de Akaike e Schwarz, com oito defasagens, apresenta problemas de instabilidade e autocorrelação nos resíduos. Segundo, o VAR restrito, que exclui a relação renda disponível/PIB, com duas defasagens, sugerido pelo critério de informação de Schwarz, satisfaz a condição de estabilidade e não apresenta autocorrelação residual. Terceiro, o VAR restrito apresenta uma estrutura mais parcimoniosa de regressores do que o VAR ampliado. Quarto e último, o teste de Chow indicou mudanças de parâmetros quando se leva em conta a relação renda disponível/PIB e se divide a amostra em dois períodos: do primeiro trimestre de 1995 ao quarto trimestre de 1999 (20 observações) e do primeiro trimestre de 2000 ao quarto trimestre de 2009 (60 observações). Uma possível razão para os problemas do VAR ampliado é a visível quebra estrutural na série da relação renda disponível/PIB, conforme o Gráfico 5 do Anexo $\mathrm{A}$. O dado utilizado referente à renda disponível é o da renda disponível bruta, segundo o IBGE (2006).

17 Cabe ressaltar que os resultados devem ser lidos com cautela devido ao reduzido tamanho da amostra.

18 O pacote utilizado na análise econométrica é o Eviews 6. 
Gráfico 1 - Consumo privado com e sem ajuste sazonal (\% do PIB)

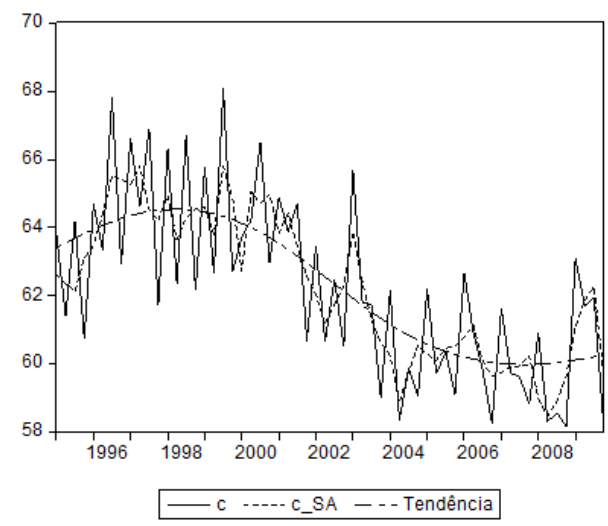

Fonte: Elaboração própria a partir de IBGE (2006).

A série trimestral do consumo do governo (g) sem e com ajuste sazonal (g_ SA) em relação ao PIB para o período em análise é mostrada no Gráfico 2. O que se nota é um aumento da amplitude da sazonalidade a partir de 2000. Tal sazonalidade pode ser decorrente do salto no empenho de despesas em dezembro de cada ano por conta dos gastos com o décimo terceiro salário. A tendência da série com ajuste sazonal apresenta leve redução até meados de 2003. Após este período, a tendência é de recuperação para o patamar inicial em torno de $21 \%$ do PIB.

Gráfico 2 - Consumo do governo com e sem ajuste sazonal (\% do PIB)

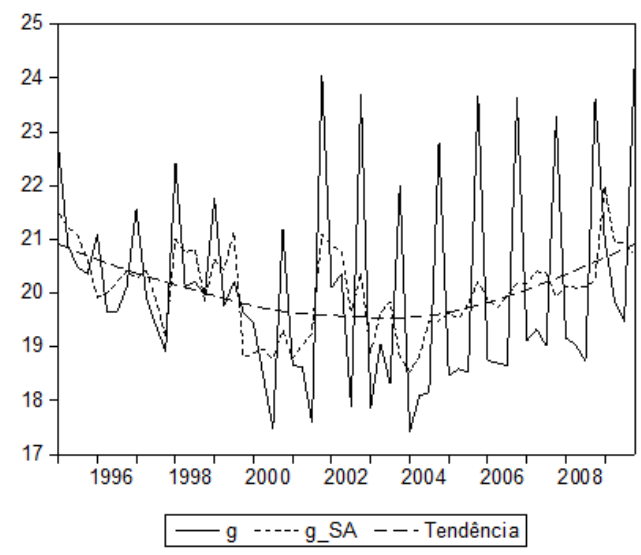

Fonte: Elaboração própria a partir de IBGE (2006). 
A série trimestral da carga tributária (t) sem e com ajuste sazonal (t_SA) em relação ao PIB é apresentada no Gráfico 3. Entre as séries estudadas, a carga tributária apresenta comportamento sazonal mais nítido ao longo de todo o período. A sazonalidade da carga pode estar associada ao padrão sazonal das receitas tributárias por conta de efeitos da legislação e da atividade econômica. Além disso, a carga tributária apresenta uma clara tendência de crescimento entre 1995 e 2006 , estabilizando-se em torno de 34\% a partir de 2007.

Gráfico 3 - Carga tributária bruta com e sem ajuste sazonal (\% do PIB)

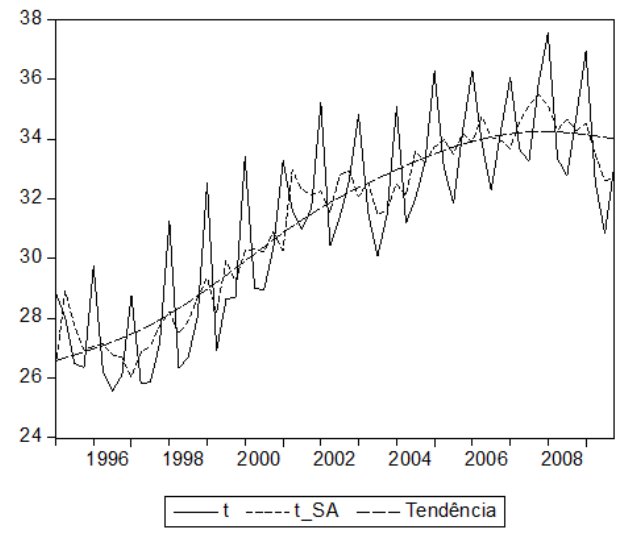

Fonte: Elaboração própria a partir de Santos et al. (2010).

Por último, no Gráfico 4 se tem a série trimestral da poupança nacional bruta (s) sem e com ajuste sazonal (s_SA) em relação ao PIB. A série da poupança se caracteriza por fortes flutuações de um trimestre para o outro. Ademais, houve uma mudança de tendência no período em análise: a poupança decresceu entre 1995 e 2001, apresentou tendência de elevação até 2006 e, após 2007, apresentou leve tendência de queda. Contudo, a tendência para todo o período é da relação poupança nacional/PIB não superar o teto de $18 \%$. 
Gráfico 4 - Poupança nacional bruta com e sem ajuste sazonal (\% do PIB)

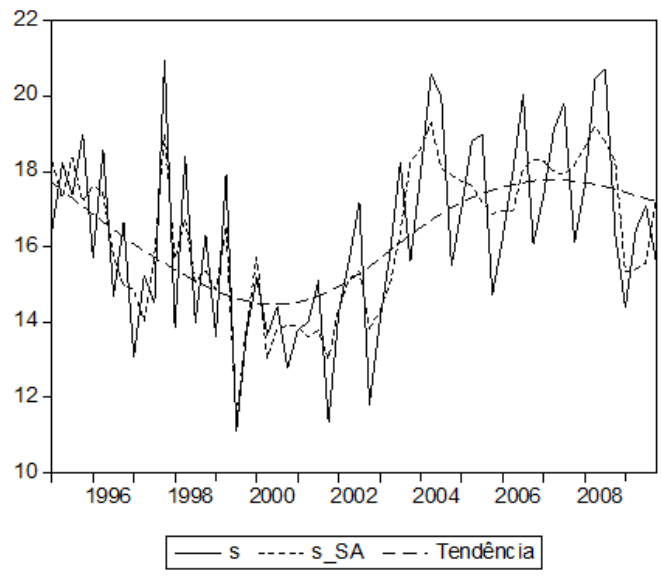

Fonte: Elaboração própria a partir de IBGE (2006).

Baseando-se em Pastore et al. (2011), pode-se dividir o período em análise em três partes. Na primeira, entre 1994 e 2001, em razão da estabilização econômica, houve explosão do consumo privado, o que levou à queda da poupança do setor privado, devido à política fiscal expansionista. Por conseguinte, a poupança doméstica decresceu ao longo do período. Na segunda, entre 2002 e 2006, o superávit fiscal do setor público se elevou a fim de controlar a relação dívida pública/ PIB, através de cortes de despesas e elevação de impostos, o que gerou aumento da poupança doméstica. Na terceira e última, entre 2007 e 2009, as autoridades elevaram os gastos públicos e estimularam o consumo privado, resultando em queda da poupança doméstica.

A partir da análise visual dos gráficos, não é possível se ter certeza sobre a existência de raiz unitária. ${ }^{19}$ Procedendo-se os testes de raiz unitária (ver Tabelas 2 e 3 no Anexo A), não se rejeita a existência de raiz unitária para as variáveis em nível. Ao se diferenciar as séries (ver Tabela 4 no Anexo A), os resultados dos testes indicam que as variáveis em primeira diferença são estacionárias, portanto os níveis são integrados de ordem I(1). ${ }^{20}$

O próximo passo é realizar a análise de cointegração. Isto é, verifica-se se as séries simultaneamente combinadas geram resíduos estacionários. O teste de cointegração de Johansen propõe dois procedimentos para se determinar o número de relações de cointegração: o teste traço e o teste máximo autovalor. Os

19 No Anexo A, nas Tabelas 2 e 3 são apresentados os resultados dos testes ADF e DF-GLS de raiz unitária.

20 Cabe lembrar que, mesmo que uma série seja estacionária, ainda assim a análise de cointegração é válida, desde que as demais séries sejam I(1). 
resultados do teste traço indicam uma relação de cointegração a 5\%. Entre as cinco especificações do teste de cointegração, considerou-se o caso que admite intercepto no vetor de cointegração e tendência linear no nível das séries (ver Tabela 5 no Anexo A).

Dado que as variáveis cointegram, pode-se estimar o modelo VEC. O modelo especificado incluiu as primeiras diferenças, $\Delta X_{t}$, sobre as diferenças defasadas de $\Delta X_{t-1}$ e $\Delta X_{t-2}$, em que $X_{t}$ é o vetor das quatro variáveis endógenas. $\mathrm{O} V E C$ com duas defasagens, com uma equação de cointegração referente à especificação que admite intercepto no vetor de cointegração e tendência linear no nível de $X_{t}$, apresenta as características desejáveis de resíduos não correlacionados e normalmente distribuídos.

$\mathrm{Na}$ falta de consenso sobre os critérios para a ordenação das variáveis no VEC, assumiu-se a seguinte ordenação: g_sa, t_sa, c_sa e s_sa. Assim, se considera a relação consumo do governo/PIB como a variável "mais exógena", enquanto a relação poupança nacional/PIB como a "mais endógena”. Justifica-se tal ordenação com base na discussão teórica na qual se assume a trajetória de gastos públicos como dada exogenamente e se propõe que a poupança privada compensa variações na poupança pública, em decorrência de mudanças na carga tributária, de tal modo que a poupança nacional mantém-se inalterada.

Como o objetivo não é analisar a relação de longo prazo existente entre as variáveis em estudo, nem analisar os coeficientes de ajustamento, os resultados do modelo VEC com duas defasagens são analisados através da função de resposta a impulsos e por meio da decomposição da variância. ${ }^{21}$

Com base nos resultados da função de resposta a impulso pode-se avaliar os impactos de choques em qualquer uma das variáveis do sistema, permitindo-se conhecer a direção e o tempo de reação das variáveis endógenas aos impulsos de um desvio padrão no sistema. A função de resposta a impulso, aplicada ao VEC com duas defasagens escolhido, foi gerada a partir do método de decomposição de Choleski. ${ }^{22}$ A Figura 1 apresenta o resultado da função de resposta a impulso do consumo privado e da poupança nacional a impulsos de um desvio padrão nas variáveis de política fiscal.

21 Observa-se que as análises da função de resposta a impulso e da decomposição da variância dependem do ordenamento das variáveis.

22 Uma crítica à decomposição de Choleski diz que os efeitos dos impulsos variam conforme a ordenação das variáveis no VEC. Conforme Pesaran e Shin (1997), a abordagem da função de resposta a impulsos generalizada não apresenta esse problema. Utilizando-se o Eviews 6, gerou-se a função de resposta a impulsos generalizada. Os resultados obtidos por ambas as abordagens convergem. Contudo, a função de resposta a impulsos generalizada apresenta duas diferenças em relação à função de resposta a impulsos das Figuras 1 e 2: o consumo privado/PIB se reduz a impulsos na carga tributária apenas após o terceiro período; e na resposta acumulada, o consumo privado/PIB apresenta queda a um choque na carga tributária apenas após o oitavo período. 
Figura 1 - Função de resposta a impulsos na carga tributária e no consumo do governo: VEC com duas defasagens
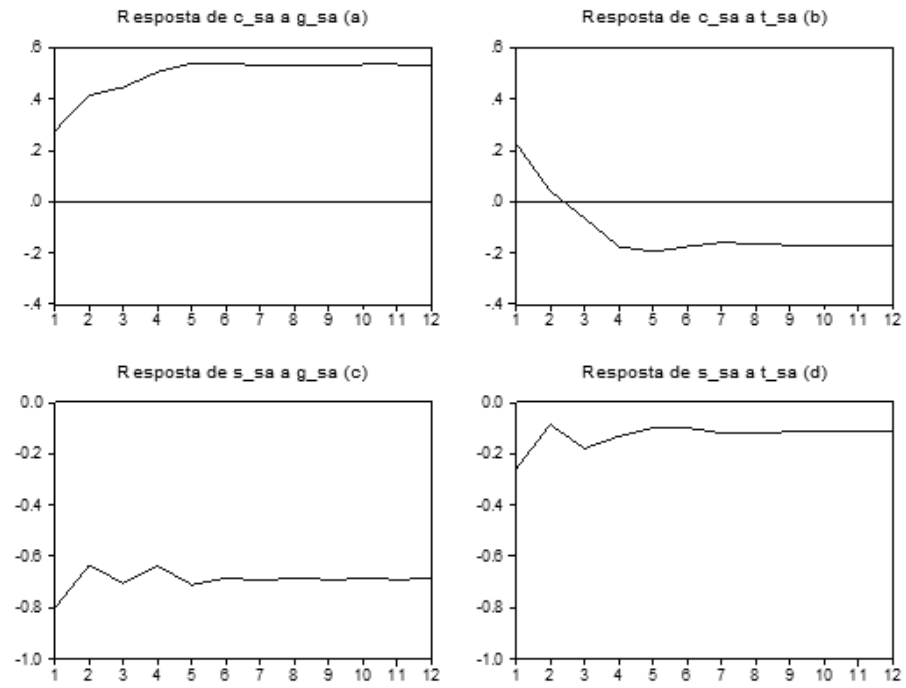

Fonte: Elaboração própria.

Na Figura 1, item a, percebe-se que a relação consumo privado/PIB se eleva em resposta a um choque de um desvio padrão na relação consumo do governo/ PIB. Nota-se que o impacto é permanente no horizonte de 12 períodos. ${ }^{23}$ Em resposta a um choque de um desvio padrão na carga tributária, item $b$, o impacto inicial sobre a relação consumo privado/PIB é de elevação. Porém, após o segundo período, a resposta se torna permanentemente negativa. Assim, pode-se afirmar que a resposta da relação consumo privado/PIB a inovações de um desvio padrão na carga tributária é desfavorável à HER. No item $c$, tem-se a resposta da relação poupança nacional/PIB a um choque de um desvio padrão na relação consumo do governo/PIB. A poupança nacional/PIB apresenta uma resposta negativa a uma inovação na relação consumo do governo/PIB no horizonte de tempo considerado. No item $d$, com exceção do quinto período, a resposta da variável poupança nacional/PIB a um choque de um desvio padrão na carga tributária é negativa ao longo do horizonte de tempo considerado. Novamente, a resposta da relação poupança nacional/PIB aos impulsos na carga tributária são desfavoráveis à HER.

23 Galí et al. (2007) encontram igual resposta do consumo a uma elevação nos gastos públicos. Segundo os autores referidos, tal efeito resulta da interação entre o comportamento de famílias que gastam toda a sua renda (e não poupam ou tomam emprestado) e a rigidez dos preços. 
A Figura 2 apresenta a função de resposta acumulada aos impulsos de um desvio padrão nas variáveis fiscais, também aplicada ao VEC com duas defasagens escolhido, a partir do método de decomposição de Choleski.

Figura 2 - Função de resposta acumulada a impulsos na carga tributária e no consumo do governo: VEC com duas defasagens
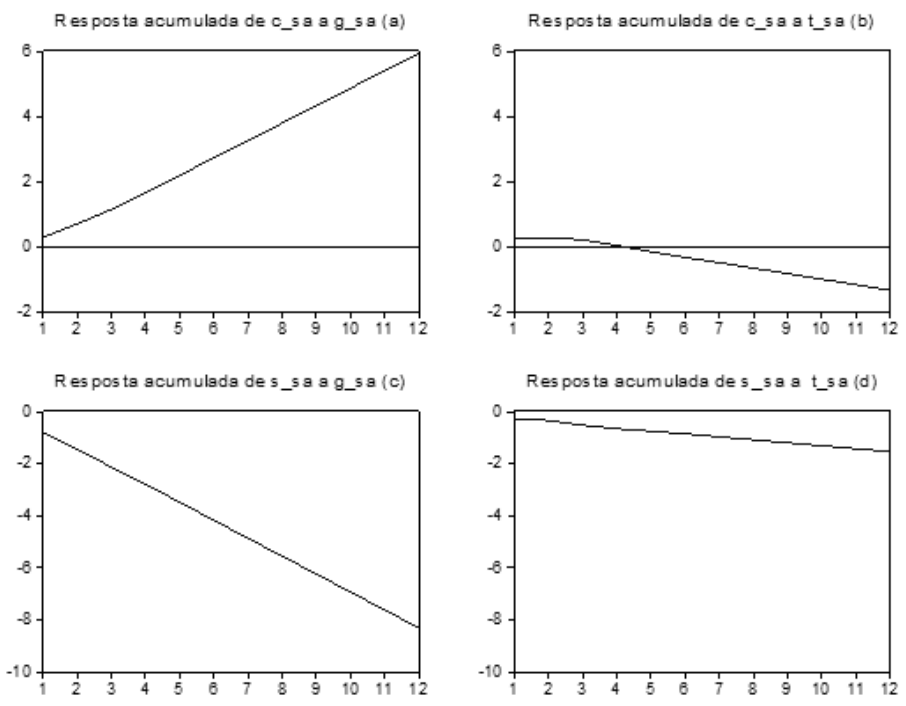

Fonte: Elaboração própria.

Como pode-se notar no item a da Figura 2, a resposta acumulada do consumo privado a um choque de um desvio padrão no consumo do governo é positiva e crescente para todo o horizonte de tempo. A resposta acumulada do consumo privado, item $b$, a um impulso de um desvio padrão na carga tributária é positiva entre os períodos 1 e 3. Todavia, após o quarto período, a resposta se torna negativa. A resposta acumulada da poupança nacional a um choque no consumo do governo, item c, é negativa para todo o período analisado. Em relação a um choque de um desvio padrão na carga tributária, item $d$, a resposta também é negativa para todo o horizonte de tempo. No entanto, o impacto negativo sobre a poupança doméstica é menos intenso no caso de um choque na carga tributária do que um choque no consumo do governo. Portanto, as respostas acumuladas das variáveis consumo privado/PIB e poupança nacional/PIB a inovações de um desvio padrão na carga tributária não corroboram a HER.

A decomposição da variância do VEC apresenta a parcela de contribuição de cada choque na variância das variáveis endógenas ao longo do horizonte de previsão. 
Na Tabela 1 tem-se a decomposição da variância do consumo privado/PIB e da poupança nacional/PIB. No intervalo de tempo considerado, a variância da relação consumo privado/PIB é explicada em boa medida por inovações na própria variável. Contudo, ao longo do tempo, ganham importância as inovações na relação consumo do governo/PIB. A relação poupança nacional/PIB tem pequena contribuição para a variância do consumo privado/PIB, enquanto a carga tributária tem uma parcela de contribuição estável ao longo do tempo.

Tabela 1 - Decomposição da variância do consumo privado/PIB e da poupança nacional/PIB

\begin{tabular}{cccccccccc}
\hline \multicolumn{4}{c}{ Consumo privado/PIB } & \multicolumn{5}{c}{ Poupança nacional/PIB } \\
\hline Periodo & g_sa & t_sa & c_sa & s_sa & Periodo & g_sa & t_sa & c_sa & s_sa \\
\hline 1 & 8,63 & 5,89 & 85,46 & 0,00 & 1 & 32,50 & 3,39 & 41,71 & 22,39 \\
2 & 17,68 & 3,81 & 78,41 & 0,09 & 2 & 35,11 & 2,50 & 45,51 & 16,86 \\
3 & 25,18 & 3,24 & 71,34 & 0,22 & 3 & 39,63 & 2,73 & 42,66 & 14,96 \\
4 & 32,02 & 4,01 & 63,18 & 0,77 & 4 & 40,55 & 2,57 & 42,19 & 14,67 \\
5 & 37,39 & 4,75 & 56,97 & 0,87 & 5 & 42,42 & 2,31 & 40,92 & 14,33 \\
6 & 41,16 & 5,03 & 52,92 & 0,87 & 6 & 43,62 & 2,13 & 40,33 & 13,90 \\
7 & 43,84 & 5,10 & 50,17 & 0,87 & 7 & 44,47 & 2,05 & 39,89 & 13,57 \\
8 & 45,91 & 5,19 & 47,98 & 0,90 & 8 & 45,04 & 1,99 & 39,62 & 13,34 \\
9 & 47,61 & 5,31 & 46,14 & 0,92 & 9 & 45,56 & 1,93 & 39,33 & 13,16 \\
10 & 49,01 & 5,41 & 44,62 & 0,94 & 10 & 45,99 & 1,87 & 39,11 & 13,01 \\
\hline
\end{tabular}

Fonte: Elaboração própria.

No caso da decomposição da variância da poupança nacional/PIB, também na Tabela 1, o que chama a atenção é a elevada parcela de contribuição dos impulsos no consumo privado/PIB. Nota-se a crescente contribuição das inovações na variável consumo do governo/PIB. Por último, observa-se a decrescente contribuição das inovações na carga tributária para explicar a variância da relação poupança nacional/PIB.

\section{Considerações Finais}

Os efeitos da política econômica e, em particular, os efeitos da política fiscal sobre a economia é um tema recorrente no debate em macroeconomia. A HER surge em qualquer discussão porque estabelece um conjunto claro de proposições testáveis empiricamente.

O presente trabalho discute os efeitos de choques na política fiscal sobre as variáveis consumo do governo/PIB e poupança nacional/PIB para o Brasil no 
período de 1995 a 2009. A partir da análise da função de resposta a impulsos e da decomposição da variância, verificou-se que as duas variáveis respondem a choques no consumo do governo/PIB e na carga tributária. Portanto, no caso brasileiro, a política fiscal importa para explicar o comportamento de variáveis macroeconômicas.

Os efeitos de choques na carga tributária brasileira não são ricardianos, porque as respostas da relação consumo privado/PIB e da relação poupança nacional/PIB a impulsos na carga tributária são negativas. Assim, no caso brasileiro, choques na carga tributária têm impactos econômicos relevantes.

Tais resultados sugerem que variações na poupança do governo não são exatamente compensadas por ajustes na poupança privada. Entre as razões para a não compensação entre os níveis de poupança, tem-se: ao tomarem suas decisões, os agentes econômicos não levam em conta a restrição orçamentária intertemporal do governo e estão sujeitos a restrições de liquidez. Tal comportamento ocorre porque os agentes econômicos recebem informações imperfeitas sobre as ações e os movimentos do governo e, ao mesmo tempo, recebem informações incompletas sobre as decisões, preferências e estratégias do governo no tocante à política fiscal. A restrição de liquidez ou a impossibilidade de recorrer ao crédito em momentos de bruscas mudanças na renda disponível leva a grandes reações da trajetória do consumo e, por conseguinte, da trajetória da poupança privada, não permitindo a perfeita compensação entre os níveis de poupança.

O presente trabalho tratou de abordar o tema proposto da maneira mais simples possível, focando apenas sobre os efeitos de choques na carga tributária e no consumo do governo. Assim, muitos assuntos ficaram de fora, como a inclusão de outras variáveis macroeconômicas no modelo e a discussão sobre os limites da análise empírica proposta.

\section{Referências}

BARRO, R. J. Federal deficit policy and the effects of public debt shocks. Cambridge: NBER, Fev. 1980. (Working paper, n. 443).

. Macroeconomics. 5. ed. Cambridge: The MIT Press, 1997.

. The behavior of US deficits. Cambridge: National Bureau of Economic Research, Mar. 1984. (Working paper, n. 1309).

. The neoclassical approach to fiscal policy. In: BARRO, R. J. (Ed.). Modern business cycle theory. Cambridge: Harvard University Press. 1989a.

. The ricardian approach to budget deficits. Journal of Economic Perspectives, v. 3, n. 2, p. 37-54, 1989b. 
BECKER, T.; PAALZOW, A. Real effects of budget deficits - theory and evidence. Swedish Economic Policy Review, v. 3, n. 2, p. 343-383, 1996.

BERNHEIM, B. D. A neoclassical perspective on budget deficits. Journal of Economic Perspectives, v. 3, n. 2, p. 55-72, 1989.

. Ricardian equivalence: an evaluation of theory and evidence. Cambridge: NBER, 1987. (Working paper, n. 1008).

BLANCHARD, O. Macroeconomia. 3. ed. São Paulo: Prentice Hall, 2004.

BUCHANAN, J.; WAGNER, R. Democracy in deficit: the political legacy of Lord Keynes. Indianapolis: Liberty Fund, 1999. Disponível em: < http://www.econlib.org/library/Buchanan/ buchCv8Cover.html>. Acesso: 26 abr. 2012.

CAVALCANTI, M. A. F. H.; SILVA, N. L.C. Dívida pública, política fiscal e nível de atividade: uma abordagem VAR para o Brasil no período 1995-2008. Economia Aplicada, v. 14, n. 4, p. 391-418, 2010.

EISNER, R. Budget deficits: rhetoric and reality. Journal of Economic Perspectives, v. 3, n. 2, p. 73-93, 1989.

FAVERO, C.; GIAVAZZI, F. Debt and the effects of fiscal policy. Boston: Federal Reserve Bank of Boston, 2007. (Working papers, n. 07-4).

GALÍ, J.; LÓPEZ-SALIDO, J. D.; VALLÉS, J. Understanding the effects of government spending on consumption. Journal of the European Economic Association, v. 5, n. 1, p. 227270, 2007.

GIAVAZZI, F.; PAGANO, M. Non-keynesian effects of fiscal policy changes: internacional evidence and the Swedish experience. Cambridge: NBER, Nov. 1995. (Working paper, n. 5332).

GRAMLICH, E. M. Budget deficits and national saving: are politicians exogenous? Journal of Economic Perspectives, v. 3, n. 2, p. 23-35, 1989.

HEIJDRA, B. J. Foundations of Modern Macroeconomics. 2. ed. New York: Oxford University Press, 2009.

IBGE. Sistema de Contas Nacionais Trimestrais Referência 2000. Rio de Janeiro: IBGE, 2006. Disponível em: <http://www.ibge.gov.br/home/estatistica/indicadores/pib/defaultcnt.shtm>. Acesso em: 20 mar. 2012.

JÖNSSON, K. Fiscal policy regimes and household consumption. Lund: Lund University, Department of Economics, 2004. (Working paper, n. 12).

LEIDERMAN, L.; BLEJER, M. I. Modeling and testing ricardian equivalence. IMF Staff Papers, v. 35, n. 1, p. 1-35, Mar. 1988.

MENDONÇA, M. J.; MEDRANO, L. A.; SACHSIDA, A. Avaliando os efeitos da Política Fiscal no Brasil: resultados de um procedimento de identificação agnóstica. Rio de Janeiro: IPEA, 2009. (Texto para discussão, n. 1377). 
MOREIRA, T. B. S. Dívida pública importa? Uma investigação empírica de modelos não ricardianos. In: ENCONTRO NACIONAL DE ECONOMIA, 38., 2010, Salvador. Anais... Salvador: Anpec. 2010. Disponível em: <http://www.anpec.org.br/encontro_2010.htm>. Acesso em: 26 abr. 2012.

PASTORE, A. C.; PINOTTI, M. C.; PAGANO, T. A. Investimentos, poupanças, contascorrentes e câmbio real. In: BACHA, E. L.; BOLLE, M. (Org.). Novos dilemas da política econômica: ensaios em homenagem a Dionísio Dias Carneiro. Rio de Janeiro: LTC, 2011.

PERES, M. A. F.; ELLERY JR., R. G. Efeitos dinâmicos dos choques fiscais no governo central no PIB do Brasil. Pesquisa e Planejamento Econômico, v. 39, n. 2, p.159-206, ago. 2009.

PESARAN, M. H.; SHIN, Y. Generalized impulse response analysis in linear multivariate models. Economics Letters, v. 58, n. 1, p. 17-29, 1998.

SACHSIDA, A.; CARLUCCI, F. N. Dívida pública afeta variáveis reais? Um teste alternativo da equivalência ricardiana por meio de testes de superexogeneidade em séries simuladas. Brasília, DF: IPEA, ago. 2010. (Texto para discussão, n. 1505).

SACHSIDA, A.; CARNEIRO, P. E. A. Capital stock, savings and public debt: are Brazilians Ricardians? Apr. 2001. Disponível em: <http://dx.doi.org/10.2139/ssrn.271814>. Acesso em: 23 abr. 2012.

SANTOS, C. H. M.; SILVA, A. C. M.; RIBEIRO, M. B. Uma estimativa de estimação da carga tributária líquida brasileira trimestral no período 1995-2009. Revista de Economia Contemporânea, Rio de Janeiro, v. 14, n. 2, p. 209-236, maio/ago. 2010.

SEATER, J. J. Ricardian equivalence. Journal of Economic Literature, v. 31, n. 1, p. 142-90, Mar. 1993.

VIEIRA, B. F. Equivalência ricardiana: evidência empírica para o Brasil. Dissertação (Mestrado em Economia) - Escola de Pós-Graduação em Economia, Fundação Getúlio Vargas, Rio de Janeiro, 2005. Disponível em: <http://bibliotecadigital.fgv.br/dspace/ bitstream/handle/10438/178/2058.pdf?sequence=1 > . Acesso em: 23 abr. 2012.

YELLEN, J. L. Symposium on the budget deficit. Journal of Economic Perspectives, v. 3, n. 2, p. 17-21, 1989. 


\section{Anexo A}

Gráfico 5 - Renda disponível e renda disponível com ajuste sazonal (\% do PIB)

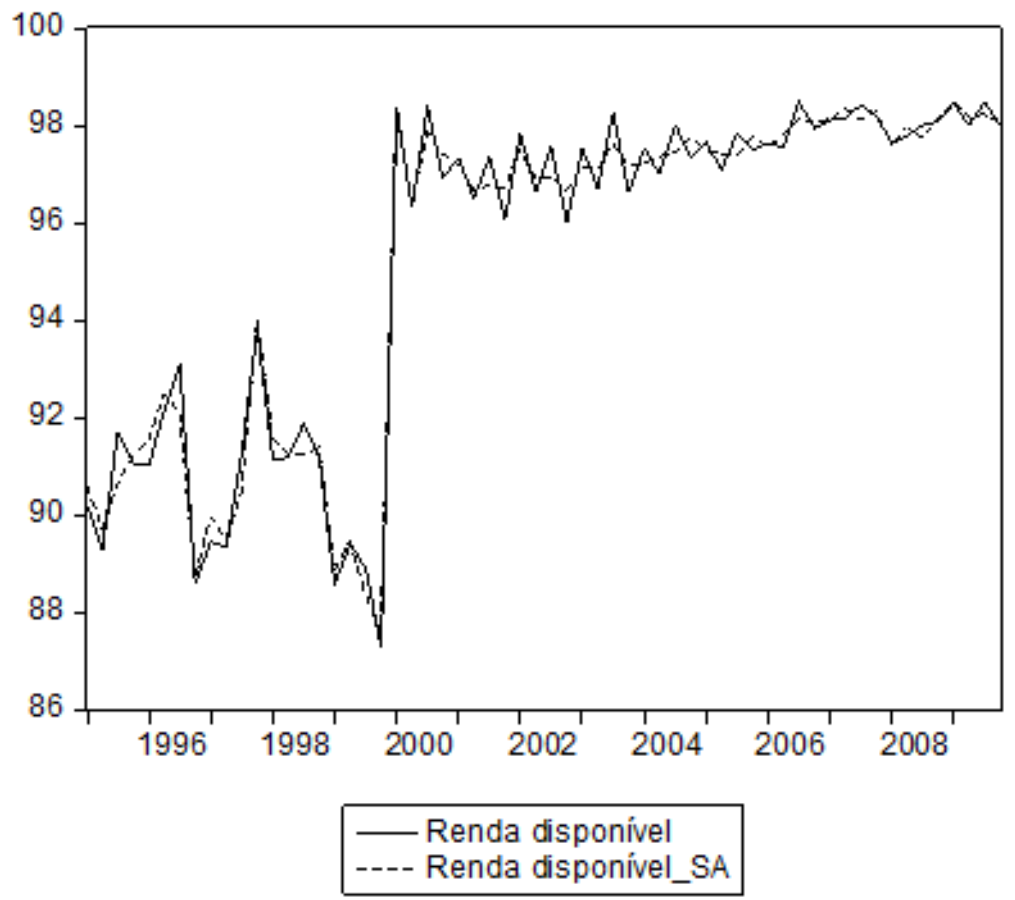

Fonte: Elaboração própria a partir de IBGE (2006).

Tabela 2 - Teste ADF

\begin{tabular}{|c|c|c|c|c|c|c|}
\hline $\begin{array}{l}\text { Variável } \\
\text { (Nivel) }\end{array}$ & $\begin{array}{l}\text { Variável } \\
\text { Exógena* }\end{array}$ & $\mathbf{p}^{* *}$ & $\begin{array}{c}\text { Estatis- } \\
\text { tica } t\end{array}$ & \multicolumn{2}{|c|}{$\begin{array}{l}\text { Valores } \\
\text { críticos }\end{array}$} & $\begin{array}{l}H_{0} \text { : variável } \\
\text { tem raiz uni- }\end{array}$ \\
\hline \multirow{3}{*}{$\begin{array}{l}\text { Consumo } \\
\text { privado/PIB }\end{array}$} & \multirow{3}{*}{$\begin{array}{l}\text { constante e } \\
\text { tendência }\end{array}$} & \multirow[t]{3}{*}{0} & \multirow[t]{3}{*}{$-3,267$} & $1 \%$ & $-4,121$ & \multirow{3}{*}{$\begin{array}{c}\text { Não rejeita } \mathrm{H}_{0} \text { a } \\
1 \% \text { e } 5 \%\end{array}$} \\
\hline & & & & $5 \%$ & $-3,487$ & \\
\hline & & & & $10 \%$ & $-3,172$ & \\
\hline \multirow{3}{*}{$\begin{array}{l}\text { Consumo } \\
\text { governo/PIB }\end{array}$} & \multirow[t]{3}{*}{ constante } & \multirow[t]{3}{*}{0} & \multirow[t]{3}{*}{-4.014} & $1 \%$ & $-3,546$ & \multirow[t]{3}{*}{ Rejeita $\mathrm{H}_{0}$} \\
\hline & & & & $5 \%$ & $-2,911$ & \\
\hline & & & & $10 \%$ & $-2,593$ & \\
\hline
\end{tabular}


conclusão.

\begin{tabular}{|c|c|c|c|c|c|c|}
\hline $\begin{array}{l}\text { Variável } \\
\text { (Nivel) }\end{array}$ & $\begin{array}{l}\text { Variável } \\
\text { Exógena* }\end{array}$ & $\mathbf{p}^{* *}$ & $\begin{array}{l}\text { Estatís- } \\
\text { tica } t\end{array}$ & \multicolumn{2}{|c|}{$\begin{array}{l}\text { Valores } \\
\text { criticos }\end{array}$} & $\begin{array}{l}H_{0} \text { : variável } \\
\text { tem raiz uni- }\end{array}$ \\
\hline \multirow{3}{*}{$\begin{array}{c}\text { Poupança } \\
\text { nacional/PIB }\end{array}$} & \multirow[t]{3}{*}{ constante } & \multirow[t]{3}{*}{0} & \multirow[t]{3}{*}{$-3,030$} & $1 \%$ & $-3,546$ & \multirow{3}{*}{$\begin{array}{c}\text { Não rejeita } \mathrm{H}_{0} \\
\text { a } 1 \%\end{array}$} \\
\hline & & & & $5 \%$ & $-2,911$ & \\
\hline & & & & $10 \%$ & $-2,593$ & \\
\hline \multirow{3}{*}{$\begin{array}{l}\text { Carga tribu- } \\
\text { tária }\end{array}$} & \multirow[t]{3}{*}{ constante } & \multirow[t]{3}{*}{1} & \multirow[t]{3}{*}{$-1,044$} & $1 \%$ & $-3,546$ & \multirow[t]{3}{*}{ Não rejeita $\mathrm{H}_{0}$} \\
\hline & & & & $5 \%$ & $-2,911$ & \\
\hline & & & & $10 \%$ & $-2,593$ & \\
\hline
\end{tabular}

Fonte: Elaboração própria.

Nota: "Variável exógena estatisticamente significativa; * "A defasagem máxima considerada foi igual a dez, $p_{\max }=10$, e pelo critério de Schwarz encontra-se a defasagem (p) considerada no teste.

Tabela 3 - Teste DF-GLS

\begin{tabular}{|c|c|c|c|c|c|c|}
\hline $\begin{array}{l}\text { Variável } \\
\text { (Nivel) }\end{array}$ & $\begin{array}{c}\text { Variável } \\
\text { Exógena* }\end{array}$ & $\mathbf{p}^{* *}$ & $\begin{array}{c}\text { Estatis- } \\
\text { tica t }\end{array}$ & \multicolumn{2}{|c|}{$\begin{array}{l}\text { Valores } \\
\text { criticos }\end{array}$} & $\begin{array}{c}\mathrm{H}_{0} \text { : variável } \\
\text { tem raiz }\end{array}$ \\
\hline \multirow{3}{*}{$\begin{array}{l}\text { Consumo } \\
\text { privado/PIB }\end{array}$} & \multirow{3}{*}{$\begin{array}{c}\text { constante e } \\
\text { tendência }\end{array}$} & \multirow[t]{3}{*}{0} & \multirow[t]{3}{*}{$-2,674$} & $1 \%$ & $-3,735$ & \multirow[t]{3}{*}{ Não rejeita $\mathrm{H}_{0}$} \\
\hline & & & & $5 \%$ & $-3,161$ & \\
\hline & & & & $10 \%$ & $-2,863$ & \\
\hline \multirow{3}{*}{$\begin{array}{c}\text { Consumo } \\
\text { governo/PIB }\end{array}$} & \multirow[t]{3}{*}{ constante } & \multirow[t]{3}{*}{0} & \multirow[t]{3}{*}{$-2,584$} & $1 \%$ & $-2,604$ & \multirow{3}{*}{$\begin{array}{c}\text { Não rejeita } H_{0} \\
\text { a } 1 \%\end{array}$} \\
\hline & & & & $5 \%$ & $-1,946$ & \\
\hline & & & & $10 \%$ & $-1,613$ & \\
\hline \multirow{3}{*}{$\begin{array}{c}\text { Poupança } \\
\text { nacional/PIB }\end{array}$} & \multirow[t]{3}{*}{ constante } & \multirow[t]{3}{*}{0} & \multirow[t]{3}{*}{$-2,579$} & $1 \%$ & $-2,604$ & \multirow{3}{*}{$\begin{array}{c}\text { Não rejeita } \mathrm{H}_{0} \\
\text { a } 1 \%\end{array}$} \\
\hline & & & & $5 \%$ & $-1,946$ & \\
\hline & & & & $10 \%$ & $-1,613$ & \\
\hline \multirow{3}{*}{$\begin{array}{c}\text { Carga tribu- } \\
\text { tária }\end{array}$} & \multirow[t]{3}{*}{ constante } & \multirow[t]{3}{*}{1} & \multirow[t]{3}{*}{$-0,088$} & $1 \%$ & $-2,604$ & \multirow[t]{3}{*}{ Não rejeita $\mathrm{H}_{0}$} \\
\hline & & & & $5 \%$ & $-1,946$ & \\
\hline & & & & $10 \%$ & $-1,613$ & \\
\hline
\end{tabular}

Fonte: Elaboração própria.

Nota: "Variável exógena estatisticamente significativa; * *A defasagem máxima considerada foi igual a dez, $p_{\max }=10$, e pelo critério de Schwarz encontra-se a defasagem (p) considerada no teste. 
Tabela 4 - Teste ADF e DF-GLS

\begin{tabular}{|c|c|c|c|c|c|c|c|}
\hline Teste & $\begin{array}{l}\text { Variável em } \\
\text { primeira }\end{array}$ & $\begin{array}{l}\text { Variável } \\
\text { exó- }\end{array}$ & $\mathbf{p}^{* *}$ & $\begin{array}{l}\text { Estatís- } \\
\text { tica t }\end{array}$ & \multicolumn{2}{|c|}{$\begin{array}{l}\text { Valores } \\
\text { críticos }\end{array}$} & $\begin{array}{c}\mathbf{H}_{\mathbf{0}}: \\
\text { variấvel }\end{array}$ \\
\hline \multirow[t]{3}{*}{$\mathrm{ADF}$} & \multirow{3}{*}{$\begin{array}{l}\text { Carga tribu- } \\
\text { tária }\end{array}$} & \multirow[t]{3}{*}{ nenhuma } & \multirow[t]{3}{*}{0} & \multirow[t]{3}{*}{$-12,116$} & $1 \%$ & $-2,604$ & \multirow{3}{*}{$\begin{array}{c}\text { Rejeita } \\
\mathrm{H}_{0}\end{array}$} \\
\hline & & & & & $5 \%$ & $-1,946$ & \\
\hline & & & & & $10 \%$ & $-1,613$ & \\
\hline \multirow[t]{3}{*}{ DF-GLS } & \multirow{3}{*}{$\begin{array}{l}\text { Carga tribu- } \\
\text { tária }\end{array}$} & \multirow{3}{*}{$\begin{array}{l}\text { constante } \\
\text { e tendên- } \\
\text { cia }\end{array}$} & \multirow[t]{3}{*}{5} & \multirow[t]{3}{*}{$-2,914$} & $1 \%$ & $-3,758$ & \multirow{3}{*}{$\begin{array}{c}\text { Rejeita } \\
\mathrm{H}_{0} \text { a } 10 \%\end{array}$} \\
\hline & & & & & $5 \%$ & $-3,180$ & \\
\hline & & & & & $10 \%$ & $-2,881$ & \\
\hline \multirow[t]{3}{*}{$\mathrm{ADF}$} & \multirow{3}{*}{$\begin{array}{l}\text { Consumo } \\
\text { privado/PIB }\end{array}$} & \multirow[t]{3}{*}{ nenhuma } & \multirow[t]{3}{*}{0} & \multirow[t]{3}{*}{$-7,933$} & $1 \%$ & $-2,604$ & \multirow{3}{*}{$\begin{array}{c}\text { Rejeita } \\
\mathrm{H}_{0}\end{array}$} \\
\hline & & & & & $5 \%$ & $-1,946$ & \\
\hline & & & & & $10 \%$ & $-1,613$ & \\
\hline \multirow[t]{3}{*}{ DF-GLS } & \multirow{3}{*}{$\begin{array}{l}\text { Consumo } \\
\text { privado/PIB }\end{array}$} & \multirow[t]{3}{*}{ constante } & \multirow[t]{3}{*}{0} & \multirow[t]{3}{*}{$-7,365$} & $1 \%$ & $-2,604$ & \multirow{3}{*}{$\begin{array}{c}\text { Rejeita } \\
\mathrm{H}_{0}\end{array}$} \\
\hline & & & & & $5 \%$ & $-1,946$ & \\
\hline & & & & & $10 \%$ & $-1,613$ & \\
\hline
\end{tabular}

Fonte: Elaboração própria.

Nota: "Variável exógena estatisticamente significativa; * A defasagem máxima considerada foi igual a dez, $p_{\max }=10$, e pelo critério de Schwarz encontra-se a defasagem (p) considerada no teste.

Tabela 5 - Teste de cointegração de Johansen: modelo 3 (intercepto na equação de cointegração e tendência linear nos dados)

\begin{tabular}{l|r|r|r|r}
\hline $\begin{array}{c}\mathbf{N}^{\circ} \text { de vetores } \\
\text { de cointe- } \\
\text { gração }\end{array}$ & Autovalor & \multicolumn{1}{c|}{$\begin{array}{c}\text { Estatística } \\
\text { Traço }\end{array}$} & $\begin{array}{c}\text { Valor crítico } \\
\text { a 5\% }\end{array}$ & Probabilidade \\
\hline Nenhum* & 0,361 & 51,15 & 47,85 & 0,0237 \\
\hline 1 Vetor & 0,236 & 25,61 & 29,79 & 0,1407 \\
\hline 2 Vetores & 0,110 & 10,24 & 15,49 & 0,2624 \\
\hline 3 Vetores & 0,060 & 3,56 & 3,84 & 0,0590 \\
\hline
\end{tabular}

Fonte: Elaboração própria.

Nota: * Rejeição da hipótese de não cointegração a $5 \%$. 